\title{
Marc Bouloiseau et les biens nationaux
}

\section{Bernard Bodinier}

\section{(2) OpenEdition \\ Journals}

Édition électronique

URL : https://journals.openedition.org/ahrf/1841

DOI : 10.4000/ahrf.1841

ISSN : 1952-403X

Éditeur :

Armand Colin, Société des études robespierristes

Édition imprimée

Date de publication : 1 décembre 2000

Pagination : 174

ISSN : 0003-4436

\section{Référence électronique}

Bernard Bodinier, "Marc Bouloiseau et les biens nationaux », Annales historiques de la Révolution française [En ligne], 322 | octobre-décembre 2000, mis en ligne le 22 mars 2006, consulté le 23 avril 2022. URL : http://journals.openedition.org/ahrf/1841 ; DOI : https://doi.org/10.4000/ahrf.1841

Ce document a été généré automatiquement le 23 avril 2022.

Tous droits réservés 


\title{
Marc Bouloiseau et les biens nationaux
}

\author{
Bernard Bodinier
}

1 C'est Albert Mathiez qui a proposé, en 1930, à Marc Bouloiseau de travailler sur les biens nationaux de seconde origine. La thèse principale ${ }^{1}$ et la thèse secondaire ${ }^{2}$, soutenues à Paris en 1935, sont publiées dès 1937. Devenu un membre influent de la “Commission Jaurès, Marc Bouloiseau a continué de s'intéresser aux biens nationaux. Ses travaux sont à situer dans le courant historiographique dirigé par Georges Lefebvre qui fut d'ailleurs son directeur de thèse.

2 On lui doit d'abord la première étude sur les biens de seconde origine que les historiens des biens nationaux ne considèrent que "comme un appendice, un complément à leurs précédentes recherches, paraissant ainsi méconnaître la place originale que les propriétés confisquées sur les émigrés, déportés, condamnés et étrangers tenaient dans l'ensemble des ventes. Il choisit le district de Rouen et aboutit aux conclusions suivantes le calendrier des ventes s'étale du 12décembre 1793 à 1809 776lots sont vendus (une centaine d'immeubles et près de 4200 ha, soit près de $5 \%$ du sol) la majeure partie (716lots et 95\% des terres) est liquidée avant la fin de 1795 les domaines ont été divisés tardivement des prête-noms se distinguent les bourgeois et urbains emportent la majeure partie des biens, ce qui n'empêche pas de nombreux petits acquéreurs de devenir propriétaires aucun individu ne profite des bons de 500livres les familles ont su protéger efficacement leur patrimoine dont elles récupèrent plus du tiers mais la noblesse sort cependant très affaiblie l'opération ne fut pas d'un bon rapport pour la République, les dépenses représentant plus de $40 \%$ des recettes. Si le travail comporte de nombreux tableaux statistiques, on peut toutefois regretter l'absence de cartes et la non-étude du milliard des émigrés sur lequel AndréGain avait mis l'accent et auquel se réfère souvent Bouloiseau.

3 L'intérêt de la thèse de Bouloiseau ne réside pas seulement dans les résultats qu'il obtient. Il se livre à une analyse très complète du phénomène vente de biens nationaux de seconde origine, ne négligeant aucun des aspects, depuis le séquestre jusqu'à la fin des ventes, en passant par la législation, l'adjudication du mobilier, les partages de pré- 
succession, le bilan financier... Et cette réflexion conduit naturellement à la publication d'une sorte de guide méthodologique et bibliographique pour orienter les recherches qui paraît en $1947^{3}$ et, de nouveau, en $1962^{4}$, tout en étant actualisé.

4 Marc Bouloiseau n'a eu de cesse que d'encourager les études sur les biens nationaux ${ }^{5}$ et il a dû éprouver une satisfaction certaine en constatant que, quelque cinquanteans plus tard, plusieurs étudiants de l'Université de Rouen entreprenaient, sous la direction de Claude Mazauric et Bernard Bodinier, de couvrir l'ensemble du département de SeineMaritime ${ }^{6}$, débordant même sur le Beauvaisis. Nul ne doute qu'il aurait aussi éprouvé de la satisfaction à voir republier les travaux de Loutchisky par le C.T.H.S. et sortir, enfin, la synthèse nationale de l'auteur de cet article sur les biens nationaux.

\section{NOTES}

1.Le séquestre et la vente des biens des émigrés dans le district de Rouen (1792-an X), Paris, Novathèse, 1937, $379 \mathrm{p}$.

2.Liste des émigrés, déportés et condamnés pour cause révolutionnaire dans le district de Rouen (1792-an X), Paris, Novathèse, 1937, $122 \mathrm{p}$.

3.Étude de l'émigration et de la vente des biens des émigrés, 1792-1827, Bulletin

d'Histoire économique et sociale de la Révolution française, 1947, pp. 25-89.

4.Étude de l'émigration et de la vente des biens des émigrés (1792-1827). Les étapes de la législation et l'utilisation des documents, id., 1962, pp.91-193.

5.Cf. sa préface à René CAISSO, La vente des biens nationaux de première origine dans le district de Tours (1790-1822), coll. de documents inédits sur l'histoire économique et sociale de la Révolution française, Paris, Bibl. nat., 1967.

6.Ces maîtrises sont parues sous une forme résumée ou commentée dans À travers la Haute-Normandie en Révolution, Rouen, Comité Régional d'Histoire de la Révolution, 1992, pp.179-251. 